\title{
CONSIDERAÇÕES SOBRE A APROPRIAÇÃO DAS NOÇÕES DE QUALIFICAÇÃO PROFISSIONAL PELOS ESTUDOS A RESPEITO DAS RELAÇÕES ENTRE TRABALHO E EDUCAÇÃO
}

Celso Joāo Ferrettĩ

\begin{abstract}
RESUMO: Examina-se neste artigo como os estudos referentes às relações entre trabalho e educação têm se valido da noção de qualificação profissional para abordar a formação geral e específica oferecida aos jovens brasileiros, pautando-se por duas matrizes orientadoras: a técnica e a sociopolítica. Tal exame reporta-se inicialmente aos momentos de predominância do taylorismo-fordismo, transitando, na seqüência, para o período em que ganham proeminência a organização e a produção flexíveis Conclui-se que tanto os que se orientam pela matriz técnica quanto os que se pautam pela sociopolítica tendem, num e noutro período, com raras exceções, a tomar por base a concepção "essencialista" de qualificação profissional. Sugere-se que as análises e os estudos sobre as relaçōes entre trabalho e educação poderiam ser refinados com a utilização do conceito de qualificação profissional como relação social, inclusive no que diz respeito à formação dos professores do ensino público.
\end{abstract}

Palavras-chave: Relações trabalho/educação. Concepção essencialista de qualificação profissional. Concepção relativista de qualificação profissional. Modelo de competências.

\section{REFLECTIONS ABOUT THE APPROPRIATION OF THE NOTIONS OF PROFESSIONAL QUALIFICATION IN STUDIES ON THE RELATIONSHIP BETWEEN WORK AND EDUCATION}

ABSTRACT: This paper discusses that the studies on the relationship between work and education have been using the notions of professional qualification to analyze the general and the vocational education of Brazilian youth according to two main thrusts, the technical and the social-political ones. The text initially refers to the taylorist-fordist period, but extends to the contemporary period in

Pesquisador sênior da Fundação Carlos Chagas e professor titular do Programa de Estudos PósGraduados em Educação da Universidade de Sorocaba (UNISO). E-mail: cferretti@fcc.org.br

Educ. Soc., Campinas, vol. 25, n. 87, p. 401-422, maio/ago. 2004

Disponível em <http://www.cedes.unicamp.br> 
which flexible production and organization have prevailed. It concludes that, independently of the period, in most of the cases, both the studies based on the technical thrust and those grounded on the social-political one, turn to the "essencialist" (or substantialist) concept of professional qualification. It is suggested that future studies on this relation should be refined by the use of the concept of professional qualification as a social relationship (or relativistic concept), including as regards public school teacher qualification.

Key words: Work/education relationships. "Essencialist" concept of professional qualification. Relativistic concept of professional qualification. Competence model.

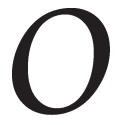

título deste trabalho sugere, por si mesmo, que as noções acima referidas não têm sua origem na área da educação. Essa constatação, mais ou menos óbvia, necessita, no entanto, ser ressaltada, pois sua apropriação pela área educacional é bastante freqüente, dado que esta, de forma menos ou mais direta, trabalha com a formação profissional, um elemento central em ambas as noções. A educação escolar, em sentido amplo, preocupada com a formação plena do indivíduo, como pessoa e como cidadão, contribui para a formação profissional de maneira indireta, seja por propiciar-lhe o acesso aos conhecimentos disciplinares, seja por entender que é parte dessa formação a compreensão do contexto em que o exercício da atividade profissional se realiza ou se realizará. A educação profissional, como recorte específico da educação escolar, dirige-se, como sabido, à formação profissional em sentido estrito, completando a formação em sentido amplo.

Os estudos sobre as relações entre o trabalho e a educação voltamse para ambas as perspectivas acima indicadas e, ao fazê-lo, valeram-se, no passado, da noção de qualificação. Atualmente se valem desta e da noção de competência, muitas vezes entendidas, erroneamente, como sinônimas. A noção de qualificação profissional situa-se no âmbito das preocupações da sociologia do trabalho e tem sido por esta exaustivamente estudada. A de competência, por seu turno, tem origem no campo econômico, mas tem sido abordada pela sociologia do trabalho, seja por conta da aproximação equivocada acima referida, seja porque as mudanças introduzidas na forma de produzir e de organizar a produção o exigiram.

Em razão das preocupações que nutre, a educação tem buscado respaldo, seja na sociologia, seja nas ciências sociais em geral, para esta- 
belecer relações entre as noções de qualificação e de competência e as práticas de formação geral e específica que desenvolve. Nesse processo nem sempre as apropriações desenvolvidas na área educacional fazem justiça ao investimento histórico realizado por diferentes disciplinas ao estudar essas noções. Neste artigo se pretende abordar tal questão, tomando por referência os desenvolvimentos ocorridos na década de 1990, remetendo-os, todavia, a períodos anteriores uma vez que as apropriaçóes acima referidas não se iniciaram nessa época. Em contrapartida, é nessa década que a área da educação produz uma inflexão significativa na sua discussão sobre as relações entre qualificação, formação geral e formação profissional em função das mudanças que ocorreram no campo do trabalho. Neste sentido, acompanhou, na sua especificidade, o movimento observado em outras áreas.

Grosso modo, pode-se dizer que a área da educação que se volta para o estudo das relações entre trabalho e educação tem historicamente se aproximado das discussóes sobre o trabalho a partir de duas grandes matrizes que se complementam e, ao mesmo tempo, dependendo do enfoque, antagonizam-se. Uma delas remete ao campo especificamente técnico, tendo orientado a formulação e o desenvolvimento das propostas de formação profissional. Dadas suas preocupações específicas e legítimas, este segmento da educação é fortemente influenciado pelo progresso técnico e, portanto, pelas mudanças técnico-organizacionais que se dão no âmbito do trabalho, respondendo não apenas a desenvolvimentos científico-tecnológicos mas, principalmente, a demandas da produção capitalista, às quais os referidos desenvolvimentos procuram dar respostas. A segunda matriz tem raízes na filosofia e na economia política de origem marxista, formulando à educação problemas de natureza econômica, filosófica, social e ético-política que remetem não apenas à formação profissional estrito senso, mas à formação humana, em sentido pleno, da qual a primeira faz parte. Em ambas as matrizes, no período histórico em que predominou a forma taylorista-fordista de produção capitalista, o olhar lançado pela área educacional à qualificação profissional foi profundamente marcado pela sua dimensão especificamente técnica, ou seja, pela visão "essencialista"1 desta, quer para justificar os procedimentos de seleção e de formação profissional, de acordo com a primeira matriz, quer para questionar, de acordo com a segunda, as demandas feitas ao indivíduo e à educação que tomavam por base a acentuada divisão técnica do trabalho. 
Considerações sobre a apropriação das noções de qualificação profissional...

A produção originária da segunda matriz influenciou, ao lado de contribuições advindas dos estudos no campo da filosofia, da história e da sociologia da educação, a orientação de muitas das análises sobre o sistema educacional brasileiro que destacaram o caráter dual e discriminatório deste, assim como seu atrelamento aos interesses econômicos. Influenciou, também, várias considerações tendo em vista a proposição de concepções educacionais que representassem não apenas um freio à segmentação do trabalho e à alienação do trabalhador sob o domínio do capital, mas o pleno desenvolvimento deste como sujeito social. Esta forma de aproximação da qualificação profissional acabou por situar em dois campos diferentes, e mesmo antagônicos, educadores e outros estudiosos que, afinal, partiam de uma mesma referência - a relação entre as demandas do capital, o avanço da tecnologia e a divisão técnica do trabalho ${ }^{2}$ - mas com perspectivas político-ideológicas muito diferenciadas.

Apesar dessas influências, pode-se afirmar, com certa ousadia, mas sem receio de cometer um erro crasso, que os conhecimentos sobre a qualificação profissional, como categoria teórica e campo de estudos, eram do domínio de poucos educadores, mesmo entre os que atuavam no campo da formação profissional, embora os estudos da sociologia do trabalho já se debruçassem sobre a questão desde a década de 1940, com as investigações de Friedmann e, posteriormente, de Naville, na década de 1950 . A ausência dessa referência teórica ou seu pouco domínio fez com que as discussões pendessem mais para os questionamentos que tinham por norte as perspectivas de natureza mais técnica (no caso do ensino profissional) ou de caráter ensaístico (no caso da formação geral), com base na economia política.

Esta última perspectiva parece ter sido influenciada, pelo menos em parte, por algumas noções derivadas da sociologia do trabalho, a saber, o esquema trifásico (Paiva, 1989) e a tese da desqualificação profissional. Segundo tal esquema, a primeira fase tem suas raízes no artesanato, que exigiria, da parte dos aprendizes, um longo processo de aprendizagem, o qual implicaria o domínio de todos os elementos envolvidos na elaboração de um produto (matéria-prima, instrumentos, métodos, processos de transformação da matéria-prima etc. e, evidentemente, a concepção do próprio produto desejado) e, da parte dos mestres, um longo e paciente processo de formação desse aprendiz. 
A segunda fase é instituída pela manufatura ao promover, em suas duas formas, a divisão técnica do trabalho. Essa divisão, de início incipiente, será progressivamente ampliada com as revoluções industriais, as quais promoverão não apenas o vínculo mais estreito do homem com a maquina, mas sua dependência dela, no que se refere à produção. Tal processo de divisão técnica do trabalho atinge seu ápice ao final do século XIX e início do século XX e seria responsável, segundo vários autores, pelo processo de desqualificação dos trabalhadores.

A terceira fase seria desencadeada pelo próprio avanço da tecnologia, a qual passaria a demandar não mais trabalhadores aptos a operar máquinas isoladas e a realizar tarefas específicas, mas capazes de supervisionar a produção realizada por estas e de controlar a articulação entre a produção de várias máquinas sofisticadas. Neste sentido, recobrar-se-ia, senão todos, pelo menos parte dos elementos que implicariam, de novo, o domínio do processo de trabalho por inteiro pelo seu executor, ou pelo menos o domínio por inteiro de fases desse processo, instituindo-se uma requalificação deste. $\mathrm{O}$ senso comum tende a vincular a terceira fase à denominada reestruturação produtiva em curso.

O esquema trifásico apresenta problemas, dos quais apontaremos alguns que nos parecem mais sérios. O primeiro reside, obviamente, em seu caráter esquemático, que faz supor fases sucessivas e progressivas do desenvolvimento da tecnologia industrial, passando por cima do caráter complexo, contraditório e não linearmente sucessivo do desenvolvimento de formas de produção e da tecnologia.

O segundo diz respeito ao vínculo direto estabelecido entre qualificação, produção industrial e tecnologia de base física, fazendo supor, de um lado, que as questóes atinentes à qualificação, se não estão restritas às atividades industriais, a elas devem se referir privilegiadamente e, de outro, que as qualificações encontram suas razões explicativas no desenvolvimento do progresso técnico. Além de desconsiderar as questões referentes ao trabalho e à qualificação presentes em outras esferas da vida econômica e social, tal esquema sugere que o que se passa com as qualificaçóes na esfera industrial pode ser tomado, legitimamente, como parâmetro para o que se passa nas outras.

O terceiro problema tem a ver com a definição implícita de um parâmetro universal do que arbitrariamente poderia ser considerado trabalho qualificado. Na medida em que o esquema sugere que a 
Considerações sobre a apropriação das noções de qualificação profissional...

desqualificação se origina na progressiva divisão técnica do trabalho, apartando-se, com isso, da elaboração por inteiro dos produtos, e uma vez que a requalificação supõe que a desqualificação pode ser superada pelo retorno, de alguma forma, ao domínio de fases inteiras da produção, o artesanato põe-se, simbolicamente, como referência de trabalho qualificado. Apesar de, evidentemente, não mais se poder tomar, nas sociedades modernas, o artesanato como referência para a produção social como um todo (embora parcelas significativas da população, mesmo em países avançados, sobrevivam com base nele), o trabalho artesanal continua a manter sua força simbólica. A questão que se levanta aqui é em que medida estão dadas, em nossas sociedades, as condições para a realização de trabalhos considerados qualificados e qual parcela da população poderá beneficiar-se dessas condições. De certa maneira esta mesma questão esteve presente nas investigações realizadas por Friedmann e Naville, assim como nos estudos de economistas e sociólogos sobre as possibilidades e os limites da automação, nos anos de 1950 e 1960. Suas reflexões não se dirigem apenas à produção industrial e aos desdobramentos do progresso técnico no que se refere à qualificação. Remetem-se, principalmente, ao desenvolvimento das chamadas, à época, sociedades pós-industriais, antecipando questôes de caráter econômico, político e social com que hoje nos defrontamos ante o vertiginoso desenvolvimento da automação.

No âmbito das discussões da área educacional sobre os desdobramentos da divisão técnica do trabalho na constituição do trabalhador e na sua qualificação profissional, as teses de Braverman (1974) sobre a desqualificação encontraram enorme acolhida, pois, ao produzirem uma ácida crítica à relação progresso técnico/desqualificação, estendendo, para um amplo e significativo setor dos trabalhadores do setor serviços, o processo de parcelarização, rotinização e degradação do trabalho que já se fizera presente desde o desenvolvimento da maquinaria, ofereciam os argumentos empíricos para evidenciar não apenas o processo de alienação a que estavam submetidos os operários e trabalhadores em certos setores dos serviços, mas também a perda de saberes que cada vez mais eram transferidos para as máquinas e os equipamentos. A resultante, na área da educação, foi o acirramento das disputas em torno da formação profissional e da formação geral e a proposição e a defesa acirrada de uma educação de caráter geral que, contrapondo-se ao duplo processo de alienação/desqualificação, promovesse a formação plena dos educandos (es- 
pecialmente os da escola pública, em função da sua extração social), a qual não só lhes proporcionaria acesso aos saberes mas, também, o desenvolvimento de uma visão crítica sobre o trabalho e as condições de seu exercício na sociedade capitalista.

$\mathrm{Na}$ década de 1980 vários educadores, ainda que não suficientemente informados sobre as discussões da sociologia do trabalho a respeito da qualificação profissional, tinham clareza dos limites enfrentados pela educação para pôr em prática tal enfoque educativo mas, ao mesmo tempo, recusavam uma visão reprodutivista a respeito da escola, por compreender seus efeitos desmobilizadores e por entender que aquela não dava conta de explicar como funciona efetivamente tal instituição.

A qualificação profissional, como categoria teórica, só passou a interessar de perto os educadores brasileiros e a mobilizá-los efetivamente quando se instalou o debate sobre os rumos que a educação viria a tomar em função das mudanças cruciais que ocorreram no campo do trabalho a partir da década de 1970 , mas que se fizeram sentir entre nós apenas na década de 1990 . Há, no entanto, uma ressalva a ser feita: os setores envolvidos com a formação profissional, em especial o “Sistema S", já haviam detectado as mudanças e experimentavam pressões para adequar-se a elas na década de 1980, o que é compreensível dada sua relação mais imediata com o setor produtivo. Neste sentido, pode-se dizer que as instituições ligadas à formação profissional se anteciparam aos educadores, que tinham como alvo de suas preocupações os sistemas públicos de ensino, quanto aos estudos sobre a qualificação profissional demandada pelas mudanças então em curso.

Aqueles dentre esses educadores que vinham argumentando em favor de uma educação que proporcionasse uma formação plena e não apenas técnico-profissional aos trabalhadores foram confrontados com a perspectiva, desenvolvida pela literatura educacional que começou a circular na época, de que tal educação não era mais defendida apenas por eles, mas pelo próprio capital, na medida em que as mudanças que vinham ocorrendo no âmbito do trabalho estariam demandando, diferentemente da empresa fordista, operários não apenas mais bem preparados tecnicamente, mas também mais bem educados, no sentido amplo do termo. O argumento central era o de que a separação teoria/ prática, concepção/execução, trabalho manual/trabalho intelectual, tão 
Considerações sobre a apropriação das noções de qualificação profissional...

criticada, já não faria sentido na empresa flexibilizada. A formação profissional e a formação geral teriam, finalmente, chegado a um ponto de articulação orgânica que seria não só desejável, mas possível. O termo utilizado para indicar esse novo estágio foi "requalificação profissional", entendido não como o processo pelo qual o trabalhador seria qualificado em atividade profissional diferente da que vinha exercendo, mas como o desenvolvimento de uma qualificação de tipo mais elevado e complexo, que contemplaria inclusive os saberes já acumulados (cf. Paiva, 1989).

Independentemente de outros desdobramentos, que serão objeto de considerações posteriores, tal conjuntura teve o condão de provocar nos educadores a necessidade de conhecer mais de perto os estudos sobre a qualificação profissional que vinham sendo realizados pela sociologia do trabalho e a de se defrontarem com o debate sobre tal categoria no âmbito dessa disciplina. Isso desencadeou na área educacional uma vasta produção de estudos bibliográficos, bem como a realização de inúmeros encontros e seminários, tendo em vista a apropriação mais sistemática e aprofundada do conceito de qualificação profissional. Desencadeou também a produção de uma literatura que se preocupou em examinar as novas formas assumidas pelo capital e as relações entre estas e os novos processos de trabalho e sua organização nas empresas flexibilizadas, bem como seus desdobramentos no que se refere à sociabilidade do trabalhador e às suas qualificações. Finalmente, estimulou os educadores a realizarem uma série de estudos empíricos que tinham por preocupação a formação do trabalhador, mas cujo locus se deslocou das escolas para as empresas, uma vez que a preocupação central era de melhor conhecer as situações de trabalho antes de acatar ou fazer proposições quanto à educação desse trabalhador. Esse triplo movimento resultou numa forte aproximação entre educadores, sociólogos do trabalho e profissionais de outras áreas afins (economistas, administradores, psicólogos do trabalho, engenheiros), assim como de sindicalistas, situação que os educadores não haviam experimentado em períodos anteriores, pelo menos na intensidade então verificada.

Não é objetivo deste artigo fazer um balanço exaustivo desse processo e da produção que daí resultou, seja pela extensão dele, seja pelas dimensões do trabalho a ser desenvolvido com essa finalidade, seja pelo tempo e pelas condições objetivas necessárias para tal. No entanto, é possível realizar uma aproximação, ainda que limitada e superficial, des- 
sa produção, por meio de publicação realizada pelo periódico Educação em Revista (2001), sob a forma de um "dossiê sobre o campo de estudos de trabalho e educação no Brasil”, na época. As informações foram colocadas à disposição por grupos com "estrutura institucional mais definida" que se dedicavam, à época, a pesquisas sobre as relações entre trabalho e educação e com os quais o Núcleo de Estudos sobre Trabalho e Educação (NETE) da UFMG, autor da solicitação, mantinha intercâmbio. $\mathrm{O}$ caráter superficial e limitado da presente aproximação decorre, em primeiro lugar, do fato de que nem todos os grupos consolidados atenderam a solicitação do NETE e, em segundo, de que, por meio das informações apresentadas, tem-se acesso ao caminho trilhado pelos grupos durante a década de 1990 , bem como das temáticas e pesquisas que eram objeto de sua preocupação, mas não à análise detalhada da produção (em grande parte sob a forma de dissertaçôes e teses, trabalhos apresentados em eventos e artigos), dado que esta não fazia parte da solicitação.

O exame das informações apresentadas permitiu algumas constataçóes. A primeira delas diz respeito ao fato de que os cinco grupos que deram retorno à solicitação ${ }^{3}$ se mostraram sensíveis, na definição de suas temáticas de investigação e de seus projetos de pesquisa, às preocupações, indagações e aos desdobramentos de caráter social e econômico mais amplos e aos de natureza especificamente educacional decorrentes, de um lado, das transformações mundiais do capitalismo mundializado e do trabalho estruturado sob sua égide e, de outro, do envolvimento do país com as políticas mundiais de natureza econômica, social e, particularmente, educacional, relacionadas a tais transformações. Praticamente todos eles pautaram seus estudos de natureza teórica ou empírica por essa referência.

A segunda constatação é a de que as matrizes que orientaram os estudos realizados em período anterior, às quais se fez menção anteriormente, continuaram a orientar os trabalhos produzidos na década de 1990, observando-se, porém, modificações nos enfoques em função do novo contexto. Assim, a matriz que se assenta sobre a formação humana, tendo por base a filosofia e a economia política, fez-se presente, mas, em vez de tomar como seu foco de análise a divisão de trabalho que se observava na forma de organização fordista da produção, escrutina o suposto, o qual considera, no geral, falso, de que as novas formas de organização do trabalho e a utilização de novas tecnologias 
Considerações sobre a apropriação das noções de qualificação profissional...

de produção descortinam a possibilidade concreta de superação dos processos de alienação a que estavam submetidos os trabalhadores, ainda que reconheça os ganhos que estes tiveram em termos de domínios sobre aspectos da sua atividade que lhes eram interditados pela forma de organização fordista. Para dar conta dessa discussão, os educadores que focam seus estudos com base nessa matriz foram obrigados a envolver-se noutra, também desencadeada pelas mudanças na forma de organização do trabalho capitalista, qual seja, a que se refere à centralidade do trabalho na constituição do humano, posto que, sob o suposto de que a automação e a informatização poriam em xeque o trabalho como categoria sociológica, bem como a organização social assentada sobre o trabalho fabril e o trabalho abstrato, toda uma nova ordem social se constituiria tendo por base os serviços e o trabalho por conta própria. Em contrapartida, a matriz estruturada com base na formação profissional foi profundamente afetada, dados o questionamento da capacitação para carreiras e ocupações específicas que vinha sendo desenvolvido e a perspectiva da formação polivalente que se desenhava como resposta a tal objeção.

A terceira constatação é a de que a discussão sobre a qualificação profissional, realizada de forma distinta e separada pelas duas matrizes anteriormente referidas (da perspectiva técnica, por parte dos educadores envolvidos com a formação profissional, e da perspectiva analítico-crítica, por parte dos que se orientavam pela matriz filosófico-econômica), permanece, de alguma forma, mas ganha outro sentido que faz com que ambas venham a convergir para um exame mais aprofundado e cuidadoso dessa categoria. Em outros termos, em função do surgimento da noção de competência na cena das discussões sobre as transformações no campo do trabalho, os educadores mais afinados com uma ou outra das matrizes viram-se na contingência, por um lado, de estudar o conceito de qualificação profissional na sua dimensão sociológica (o que não havia ocorrido antes, no seu âmbito, de forma sistemática e aprofundada, embora fosse objeto desse tipo de consideração por parte da sociologia do trabalho). Por outro lado, foram instados a analisar as relações entre os dois conceitos, seja para rever os enfoques da formação profissional, da perspectiva técnica, seja para poder operar a crítica de caráter filosóficoeconômico acima referida. Finalmente, em virtude do peso atribuído à formação escolar na constituição do trabalhador para desempenhar-se a contento, segundo os novos paradigmas produtivos preconizados, e em conseqüência, também, da valorização atribuída à sua subjetividade, pe- 
las mesmas razões, os educadores viram-se obrigados, por concordar com os argumentos dispostos pelos formuladores de tais paradigmas, ou para criticá-los, a mergulhar numa seara da qual tinham um conhecimento precário ou vago. Este movimento, presente em todos os grupos que ofereceram as informações, pode ser considerado um subproduto positivo das mudanças engendradas pelo capitalismo atual para os estudos sobre a relação trabalho/educação.

A quarta constatação é a de que os educadores que, por dever de ofício, sempre estiveram às voltas com as políticas e reformas educacionais viram-se na contingência de, mais uma vez, mergulharem nessa discussão, com a ressalva de que os mais diretamente envolvidos com as relações entre educação e trabalho (aqueles que atuam no ensino médio e no ensino técnico) não haviam sido convocados a ela por quase 20 anos, uma vez que, até o início das discussões dos anos de 1990, vigoravam as determinações da Lei n. 5692/71, com as idas e vindas decorrentes das críticas a que foi submetida. Por essa razão, o debate sobre as políticas educacionais do Governo FHC foi objeto de muito trabalho de reflexão ensaísta e de pesquisa empírica, seja por conta das origens dessas políticas e do jogo político que as instituiu, seja por conta das conseqüências antevistas pelos educadores, posteriormente confirmadas, relativas ao perigo que poderiam representar para a qualidade do ensino público, seja pelo seu atrelamento instrumental aos interesses dos setores produtivos, seja pela desresponsabilização progressiva do Estado quanto à garantia do direito subjetivo de acesso à educação. Esse debate, central para os educadores, articulou em torno de si muitas das produções voltadas para as diferentes temáticas privilegiadas pelos grupos (crises do capitalismo contemporâneo e transformações na sociedade e no trabalho, formação humana, qualificação profissional, políticas de emprego e renda, relações trabalhistas, constituição de formas alternativas ao trabalho assalariado, demandas à educação e seus desdobramentos em termos de práticas pedagógicas e formação de professores, financiamento do ensino etc.).

A quinta constatação é a de que um tema pouco tratado na produção que antecedeu a década de 1990 - o do trabalho alternativo ao assalariado -, anteriormente encarado sob a forma de trabalho informal, ganhou espaço de discussão entre os grupos em função da denominada flexibilização quantitativa e do desemprego estrutural crescente. A organização dos trabalhadores em cooperativas e a 
Considerações sobre a apropriação das noções de qualificação profissional...

assunção, por estes, da autogestão de empresas falimentares, como forma de sobrevivência, aliadas à ênfase posta pelo discurso governamental no "empreendedorismo" e no trabalho por conta própria, motivaram integrantes de mais de um grupo a pesquisar tais dimensóes do trabalho que, embora não exercido sob forma especificamente capitalista, está submetido às injunções desse modo de produção.

A sexta constatação remete aos estudos sobre a ação sindical ante a educação geral e a formação profissional dos trabalhadores em função da necessidade, admitida pelos próprios sindicatos, de rever algumas de suas pautas perante as transformaçóes ocorridas no âmbito do trabalho e, particularmente, ante o desemprego. No caso brasileiro, essa necessidade levou as centrais sindicais a encararem como fulcral uma prática anteriormente embutida na formação sindical, de forma um tanto secundarizada, qual seja, a da formação profissional. Tal circunstância motivou intensamente as centrais, que terminaram por formular programas, seja de educação geral, associada à formação profissional (CUT), seja especificamente desta (CGT e Força Sindical), no âmbito do Programa Nacional de Qualificação (Planfor). A participação das centrais nesse programa, como beneficiárias das verbas a ele alocadas pelo Governo FHC, via MTE, e como membros do CODEFAT, que administrava tal alocação, o envolvimento intenso do sindicato com a formação profissional, assim como os questionamentos sobre o sentido político do PLANFOr e sobre a qualidade e eficiência dos cursos oferecidos, motivaram os grupos ao estudo dessa temática, que se tornou central em alguns deles.

Finalmente, foi possível verificar que, apesar de envolvidos com as temáticas indicadas nas constatações anteriores e resumidas no parágrafo acima, os grupos diversificaram-se em torno das ênfases emprestadas a algumas delas. Embora o tema da formação humana estivesse presente em todos os grupos, foi assumido de forma nuclear por três deles, com base na filosofia e na economia política; o tema da qualificação profissional, discutido com base na sociologia do trabalho, esteve presente em todos, mas foi assumido especificamente por um deles; a temática do trabalho alternativo, especialmente sob a forma de cooperativas rurais e urbanas, foi desenvolvida principalmente por dois grupos; a ação sindical, em termos de educação e, especialmente, de formação profissional, percorreu todos os grupos, mas foi objeto central de apenas um deles; apenas um grupo atribuiu papel 
central aos estudos históricos a respeito do trabalho e dos trabalhadores no Brasil, indicando que esta temática necessita ser trabalhada com mais intensidade.

No entanto, chama a atenção o fato de que a aproximação entre os educadores e outros especialistas, especialmente os sociólogos do trabalho, não parece ter interferido significativamente no olhar lançado pelos primeiros à qualificação profissional. Explicando melhor: destacou-se anteriormente que os educadores que produziam a discussão sobre as relações trabalho/educação, quando predominavam as formas fordistas de produção, operavam, quer para justificá-las, quer para criticá-las, com o registro da concepção “essencialista” de qualificação. Pois bem, esse registro não parece ter sofrido alterações significativas em função da convivência com a literatura da sociologia do trabalho sobre a qualificação, a não ser com raras exceções, conforme me foi possível aquilatar da leitura, por dever de ofício, de um grande número de dissertaçôes e teses e de trabalhos apresentados em eventos. As perguntas que cabem, diante dessa circunstância são: Por que a visão não se altera, ou pouco se altera? Qual a importância de uma visão mais completa e complexa da qualificação profissional por parte dos educadores?

Quanto à primeira questão é necessário chamar a atenção para uma ausência, durante muito tempo, de pleno consenso entre os próprios sociólogos do trabalho, do conceito, dada sua polissemia. Faz parte do debate a distinção entre a concepção "essencialista" e "relativista" de qualificação profissional. A primeira, a que já nos referimos anteriormente, é contraditada por aqueles que se recusam a olhar a qualificação da perspectiva estreita da adequação/readequação entre, de um lado, progresso técnico, mudanças no conteúdo e no processo de trabalho, qualificações do posto de trabalho e, de outro, a qualificação do trabalhador, especialmente quando os dois últimos termos são reduzidos, respectivamente, a um rol de tarefas e a uma lista de atributos pessoais. Os que criticam o ponto de vista "essencialista" adotam a concepção que denominam de "relativista", em que "a qualificação resulta das relações sociais entre classes dentro e fora da empresa, que se traduzem em um sistema de codificação social - qualificações - que organiza o sistema de remuneração do trabalho" (Lope Peña \& Martín Artiles, 1992, p. 3). Tal concepção, a começar por Naville (1956), é defendida por vários autores franceses (por exemplo: Dadoy, 1984; 
Considerações sobre a apropriação das noções de qualificação profissional...

Paradeise, 1987; Rolle, 1989), mas não apenas por eles (Villavicencio, 1992, por exemplo), com diferentes nuanças.

O dissenso não se dá apenas entre os que defendem concepções tão diversas como as acima mas, também, no interior de cada uma delas. Entre os "essencialistas", por exemplo, a tese de Freyssenet sobre a qualificação/desqualificação da força de trabalho, publicada em 1974, entra em choque com a de Touraine. Quanto aos "relativistas", as diferenças dão-se entre os que entendem as relações sociais como relações entre classes e os que as entendem como relações entre grupos. A crítica destes últimos aos primeiros é a de que, ao enfocarem as qualificações da perspectiva da classe, tomam a esta como homogênea, não dando, por isso, conta de interesses coletivos (grupais) ou individuais em seu interior. Os primeiros criticam os segundos por atribuírem tanta importância aos interesses grupais e individuais que secundarizam a determinação de classe.

Villavicencio, em suas ponderações sobre a dificuldade encontrada não apenas pela sociologia, mas também pela psicologia, pela economia do trabalho e pela ergonomia, entre outras, para chegar a um conceito plenamente aceito de qualificação profissional, considera que esta

não pode ser compreendida como uma construção teórica acabada, mas, sobretudo, como um conceito explicativo da articulação de diferentes elementos no contexto de relaçóes de trabalho, capaz de dar conta das regulações técnicas que ocorrem na relação dos trabalhadores com a tecnologia e das regulações sociais que produzem os diferentes atores da produção que resultam nas formas coletivas de produzir. (Villavicencio, 1992, p. 1)

Daí sua proposição de que a qualificação seja entendida como uma noção heurística. Nos anos mais recentes, a ênfase atribuída à educação, ainda que fortemente centrada nos aspectos cognitivos, parece, no entanto, visar menos às contribuições que esta pode oferecer à capacitação técnica e mais àquelas que se referem à preparação dos trabalhadores para enfrentar o que Villavicencio denomina de dimensão aleatória do trabalho, ou seja, aqueles elementos que escapam ao âmbito do trabalho prescrito, cada vez mais presentes quando a produção se rege pela flexibilidade.

Aqui surge em cena o elemento novo no debate sobre a qualificação, apoiado na valorização que a produção capitalista passa a em- 
prestar à flexibilidade na produção. Contrariamente ao que se dava no taylorismo-fordismo, o saber construído pelos trabalhadores no cotidiano da fábrica passa não apenas a ser reconhecido como requisitado e premiado. O chamado saber tácito, ou qualificação tácita, oriundo da experiência dos trabalhadores individuais e do coletivo do trabalho, ganha proeminência porque se reconhece sua força para a resolução dos problemas diários com que a produção se defronta. A valorização desse saber e sua incorporação à produção recebem um nome - modelo de competências -, em que estas significam não apenas o saber/fazer, o domínio do conhecimento técnico, mas, principalmente, o saber/ser, a capacidade de mobilização dos conhecimentos (não apenas técnicos) para enfrentar as questóes problemáticas postas pela produção.

O modelo de competências surge, assim, em função da adoção de um novo paradigma produtivo que promove a crise dos postos de trabalho e obriga a repensar a qualificação. Mas, como diz Hirata (1994, p. 133), trata-se de um modelo "difícil de pôr em prática se não se verificam soluções (...) a toda uma série de problemas, sobretudo o de um desenvolvimento não remunerado (nossos grifos... quais?) das competências dos trabalhadores na base da hierarquia", envolvidos na gestão participativa, "sem ter necessariamente uma compensação em termos salariais".

A "novidade" trazida ao debate sobre a qualificação pela reestruturação produtiva apoiada nos paradigmas da flexibilização/integração, todavia, não é assim tão nova. $\mathrm{Na}$ verdade, faz de novo pender a balança para o enfoque "essencialista" da qualificação, ou seja, para a concepção clássica da sociologia do trabalho. $\mathrm{O}$ passo à frente, neste caso, consiste em repor o debate pelo menos na perspectiva "relativista". Isso implica tratar a questão de forma muito diversa da que vem sendo feita e, certamente, iluminada pela crítica à economia política e pela sociologia, voltadas para o conteúdo e para o processo do trabalho no interior da fábrica, bem como para o construto social produzido no âmbito dos processos de reprodução fundados no trabalho.

As consideraçôes acima podem ajudar a entender, em parte, as razões pelas quais os educadores permaneceram, no geral, e aparentemente continuam presos à concepção "essencialista" de qualificação profissional. Mas às razões aventadas podem ser adicionadas pelo menos mais duas. A primeira tem a ver com a tendência, que se fortaleceu na década de 1990, tanto na literatura educacional quanto na da econo- 
Considerações sobre a apropriação das noções de qualificação profissional...

mia, da administração de empresas, da psicologia e mesmo da sociologia, de priorização do conceito de competência em detrimento do de qualificação, ainda que por diferentes razóes. Houve muita literatura nessas áreas que, considerando o conceito de competência, e as ações de formação nela baseadas, o estágio mais avançado em termos educacionais, priorizou seu estudo e sua adoção. Em contrapartida, especialmente entre os educadores que adotaram uma postura crítica com relação ao conceito, houve muita produção dedicada ao seu desmonte. A sociologia do trabalho não cometeu, no entanto, o equívoco bastante presente nas outras áreas, de entender os dois conceitos como sinônimos. $\mathrm{Na}$ área educacional, especialmente naqueles setores menos ligados aos estudos acadêmicos sobre as relações entre educação e trabalho, e particularmente naqueles ligados ao ensino médio e ao ensino técnico, grassou a substituição, por sinonímia, de um conceito por outro, provavelmente por efeito dos documentos oficiais e legais de proposição e regulamentação das reformas nessas duas modalidades de ensino. O Ministério do Trabalho também contribuiu para tal por intermédio de suas ações no âmbito da educação profissional de nível básico.

A segunda razão pela qual um conceito mais refinado de qualificação profissional (o relativista) não se difundiu entre os educadores diz respeito, no nosso entender, à própria complexidade dele e às dificuldades inerentes à sua utilização prática ou à sua incorporação como categoria analítica na pesquisa empírica. Parte dessa dificuldade decorre do fato de que não faz sentido estabelecer distinções práticas entre as concepções "essencialista" e "relativista" de qualificação profissional pois essa distinção é apenas teórica. Quando Friedmann e Naville realizavam seus estudos não se limitavam, na prática, a estabelecer relações diretas e mecânicas entre inovações tecnológicas e qualificações, até porque nenhum deles se restringe unicamente ao exame de como as inovações afetam o processo e a organização do trabalho fabril e mesmo dos serviços. Trata-se mais de uma questão de ênfase, a qual tende a ressaltar os efeitos do avanço do progresso técnico sobre a qualificação técnica dos trabalhadores em detrimento de outros aspectos.

Poder-se-ia considerar, por isso, que o privilegiamento da abordagem essencialista se deveria ao fato de que tais autores realizam o exame da qualificação no âmbito do fordismo e da estreita relação entre o posto de trabalho e o desempenho das tarefas que lhe são adstritas. Isso conferiria enorme importância às características técnicas das tarefas e, 
por isso, aos requisitos técnicos da força de trabalho necessários à sua realização. Uma objeção a este argumento é a de que, mesmo com a tendência à diluição dos postos de trabalho observada a partir das inovações tecnológicas e organizacionais que passam a ocorrer com a denominada reestruturação produtiva, muito da literatura recente sobre as qualificações dos trabalhadores continua a circunscrever-se ao enfoque essencialista, ainda que priorizando aspectos anteriormente pouco considerados (por exemplo, o trabalho mental e as "qualificaçôes sociais"). Em contrapartida, no âmbito do fordismo, o posto de trabalho é elemento central para a análise em ambos os enfoques, uma vez que a partir dele se organiza a produção no período em que os autores considerados tratam da qualificação.

A discussão a partir do posto de trabalho não parece constituir, portanto, um encaminhamento adequado da questão posta anteriormente, apesar de a diluição tendencial dos postos conduzir ao debate sobre as semelhanças e diferenças entre os conceitos de qualificação e competência. Parece mais razoável considerar que o elemento distintivo reside no fato de que, na concepção relativista, a ênfase desloca-se do plano das relações entre o avanço das forças produtivas e a adequação de um dos elementos da reprodução da força de trabalho (seu aprimoramento, como valor de uso, pela via da qualificação) para, incluindoo, centrar-se sobre as relações de produção, o que implica, necessariamente, tratar a qualificação profissional no âmbito da correlação de forças capital/trabalho.

Todavia, mesmo desse ponto de vista, o olhar pode ser guiado pela perspectiva da relação entre desenvolvimento tecnológico e qualificação técnica, como o faz, por exemplo, Braverman. Poder-se-ia dizer que esse é o tipo de olhar que, privilegiando um aspecto importante das relações de produção, fixa-se nele, produzindo uma leitura economicista dessas mesmas relações. No entanto, mesmo sob este aspecto, há possibilidades que se descortinam, como, por exemplo, as relacionadas ao exame dos critérios econômicos para a definição de sistemas classificatórios e de hierarquização de profissões.

No entanto, esse possível viés não deveria impedir ou prejudicar o desenvolvimento das potencialidades teóricas e investigativas da concepção da qualificação como relação social. Em outros termos, o conceito ampliado de qualificação derivado do enfoque relativista descortina, a nosso ver, a possibilidade de tratar a qualificação não 
Considerações sobre a apropriação das noções de qualificação profissional...

apenas no plano econômico, mas também no político e no cultural. Por exemplo, os critérios econômicos utilizados para a definição dos sistemas classificatórios e das hierarquias poderiam ser trabalhados também a partir dos critérios sociais, culturais e ideológicos, que não apenas matizam aqueles mas introduzem variações nas classificações e nas suas transformações históricas, permitindo compreender como se estruturam, coletivamente, relações de trabalho que envolvem, entre outras, a definição de salários e de condições do exercício profissional, bem como as estruturas de poder no interior das organizações produtivas e destas com as organizações dos trabalhadores. Deriva dessas possibilidades a importância da concepção relativista para os educadores que se proponham a analisar as relações entre trabalho e educação tendo por referência o conceito de qualificação profissional.

Talvez residam aí a força e a fraqueza dessa concepção. A força decorre do fato de que se poderá, dessa forma, entender a qualificação como síntese de múltiplas determinações, sempre cambiante, ela própria, assim como tais determinações, e sempre inacabada, como sugere Villavicencio (1992). A fraqueza está em que, entendida dessa forma, a investigação sobre a qualificação, se se torna mais promissora e instigante, põe-se, também, como mais complexa e mais difícil. Esta não é uma questão de somenos importância, tanto do ponto de vista teórico quanto do metodológico. No plano teórico a concepção traz à baila a necessidade de definição de categorias explicativas, assim como de delimitaçôes, dada a amplitude adquirida pelo conceito. No plano metodológico, as dificuldades remetem à definição de enfoques investigativos, assim como à elaboração de instrumentos suficientemente sensíveis para captar as informações necessárias. É possível que, entre outras, esta seja uma das razóes pelas quais a abordagem relativista da qualificação, da qual a concepção da qualificação como relação social é tributária, tem encontrado dificuldade para se firmar, ainda que vários estudos desenvolvidos na França procurem nela se pautar, provavelmente pela grande importância que nesse país é conferida às convenções coletivas sobre o exercício profissional, por meio das quais são reguladas, no plano social mais amplo, assim como no da produção, as relações capital/trabalho.

$\mathrm{O}$ enfoque da qualificação como relação social, sem abandonar o exame das relações entre a qualificação do trabalhador e as demandas da inovação tecnológica, antes tomando-a como elemento impor- 
tante, confere prioridade ao exame do conceito no âmbito das relações sociais de produção e, neste sentido, enriquece-o. Sob esse ângulo, pode-se dizer que a concepção relativista incorpora a essencialista ampliando-a, conferindo maior importância à qualificação como relação social.

Se a incorporação do conceito de qualificação profissional como relação social ao estatuto da pesquisa pode representar uma dificuldade para os educadores, ao mesmo tempo que um saudável desafio, há necessidade de considerar ainda dois outros desafios, se se pretender, como um objeto legítimo de pesquisa, a qualificação profissional dos educadores que militam na escola.

O primeiro deles não é meramente acadêmico, mas político, uma vez que, pelo menos no caso dos professores, o MEC já tomou providências no sentido de promover sua capacitação segundo o enfoque priorizado pelas políticas educacionais do Governo FHC voltadas para a formação técnico-profissional, a saber, a formação contínua, baseada no modelo de competências. Tal como expresso no documento que define os referenciais para a formação dos professores:

É consenso que nenhuma formação inicial, mesmo em nível superior, é suficiente para o desenvolvimento profissional, o que torna indispensável a criação de sistemas de formação continuada e permanente para todos os professores. (MEC/SEF, 1999, p. 17, nosso grifo)

O grifo pretende chamar a atenção para o fato de que algo decidido no plano técnico-burocrático é atribuído à vontade e ao interesse da comunidade dos educadores e da sociedade em geral, como sugere a assertiva de que "um novo papel de professor está sendo gestado a partir de novas práticas pedagógicas, da atuação da categoria e da demanda social" (idem, p. 16). Embora não descarte a formação inicial pela sua necessidade evidente, as atuais políticas tendem, pelo menos no presente momento, a valorizar sobremaneira a formação continuada, valendo-se, em ambos os casos, do modelo de competências. Tal valorização prende-se ao fato de que os professores que hoje atuam nas escolas públicas obtiveram formação precária e não condizente com o modelo do qual se supõe que devam valer-se em sua ação profissional, de acordo com as novas políticas, ou seja, o modelo de competências. 
Considerações sobre a apropriação das noções de qualificação profissional...

O segundo desafio põe-se a partir da seguinte questão: Como encarar a qualificação dos professores se estes, diferentemente dos operários, que são os sujeitos dos processos qualificantes discutidos pela sociologia do trabalho, não atuam no mesmo contexto daqueles, ou seja, na empresa, e especialmente a empresa fabril, mas sim no setor de serviços, mais precisamente nos serviços públicos? Faria sentido discutir sua qualificação profissional (não simplesmente sua formação por competências) segundo os mesmos parâmetros que vêm sendo utilizados para a formação dos trabalhadores dessas empresas?

Sem pretender, evidentemente, oferecer qualquer resposta definitiva a essas questões (e a outras que delas podem ser derivadas), convém chamar a atenção para algumas ponderaçôes. A primeira refere-se ao fato de que a própria definição do setor de serviços é problemática, restringindo-se, predominantemente ao que Offe denominou de "definições residuais", e que outros denominam de definição pelo negativo: "O setor serviços abrange tudo que não está incluído na produção extrativa e de transformação" (Offe, 1991, p. 11). A segunda ponderação diz respeito ao fato de que o trabalho do professor se desenvolve num contexto muito particular, caracterizado pela instituição escolar pública. ${ }^{4}$ Trata-se, portanto, de uma situação muito específica. Nesse caso cabe retomar uma formulação de Villavivencio (1992) que, embora referida originalmente à empresa fabril, parece caber aqui, feitas as devidas reformulações para adequá-la ao exame da qualificação do professor. Segundo esse autor, que se alinha com a concepção da qualificação como construção e relação sociais, a melhor forma de compreendê-la e estudá-la reside na análise da situação de trabalho, pois aí se desenrola a trama de relações sociotécnicas implicada na realização das atividades profissionais. Tal enfoque, aplicado à escola, demanda o conhecimento de como aí está organizado o trabalho, de quais as redes de relaçôes que nela se constroem, de como se dá o processo de intercâmbio de saberes, de quais comportamentos vão sendo definidos em razão do exercício da docência, de como se estruturam relações de mando e poder etc., compreendidos não apenas no seu acontecer atual mas na constituição histórica da cultura escolar em que estão envolvidos. Como se pode notar, a qualificação do professor, encarada desta perspectiva, é algo muito mais complexo e desafiador do que supõe a vã filosofia do modelo de competências.

Recebido em junho de 2004 e aprovado em julho de 2004. 


\section{Notas}

1. Sem nenhuma pretensão de dar conta deste enfoque, pode-se dizer que a concepção "essencialista" de qualificação profissional está diretamente relacionada ao progresso técnico. Segundo tal concepção, o desenvolvimento da tecnologia demanda, a cada momento, que o trabalhador desenvolva novas habilidades e conhecimentos que lhe permitam lidar adequadamente com os avanços tecnológicos. Ainda que correta, esta concepção de qualificação profissional é restrita, como se verá posteriormente.

2. Certamente não escapavam a boa parte desses estudiosos as questões relacionadas à divisão social do trabalho. Entretanto esta não parecia ocupar, pelo menos entre os educadores, o centro das preocupaçóes.

3. Núcleo de Estudos, Documentação e Dados sobre Trabalho e Educação (NEDATE), da Universidade Federal Fluminense; Grupo Trabalho-Educação, da Fundação Carlos Chagas e da Pontifícia Universidade Católica de São Paulo; Núcleo Trabalho e Educação, do Programa de Mestrado e Doutorado em Educação da Faculdade de Educação da Universidade Federal do Ceará (nTe/ufce); Linha de Pesquisa em Trabalho e Educação, do Programa de Pós-Graduação em Educação da Universidade Federal de Santa Catarina; e Núcleo de Estudos sobre Trabalho e Educação, da Faculdade de Educação da Universidade Federal de Minas Gerais (NETE/UfMG).

4. Embora o professor da escola pública não exerça sua atividade profissional apenas no setor público, pelo menos no caso brasileiro, é o desempenho de seu mister nesse espaço que nos interessa aqui.

\section{Referências bibliográficas}

BRASIL. Ministério de Educação. Secretaria de Educação Fundamental. Referenciais para formação de professores. Brasília: MEC; SEF, 1999.

BRAVERMAN, H. Trabalho e capital monopolista. Rio de Janeiro: Zahar, 1974.

DADOY, M. Qualification et strutures sociales. CADRES, Paris, n. 313, juin 1984.

EDUCAÇÃO EM REVISTA, Belo Horizonte, n. 33, jun. 2001.

FRIEDMANN, G. Oú va le travail?. Paris: Gallimard, 1950.

FRIEDMANN, G. O trabalho em migalhas. São Paulo: Perspectiva, 1964.

HIRATA, H. Da polarização das qualificações ao modelo da competência. In: FerRetTi, C.J. et. al. Novas tecnologias, trabalho e educação: um debate multidisciplinar. 2. ed. Petrópolis: Vozes, 1994.

Educ. Soc., Campinas, vol. 25, n. 87, p. 401-422, maio/ago. 2004

Disponível em <http://www.cedes.unicamp.br> 
LOPE PEÑA, A.; MARTÍN ARTILES, A. Cambio técnico y procesos de recualificación. Trabalho apresentado no 4. Congreso Español de Sociologia, Madrid, 1992.

NAVILLE, P. Essai sur la qualification du travail. Paris: Riviere, 1956.

OFFE, C. Trabalho e sociedade: problemas estruturais e perspectivas para o futuro da sociedade do trabalho. Rio de Janeiro: Tempo Brasileiro, 1991. v.2

PAIVA, V. Produção e qualificação para o trabalho: uma revisão da bibliografia internacional. 1989 (mimeo).

PARADEISE, C. Des savoirs aux competences: qualification et régulation des marchés du travail. Sociologie du Travail, Paris, v. 29, n. 1, p. 35-46, 1987.

ROLLE, P. O que é qualificação do trabalho. In: Hirata, H. (Org.). Divisão capitalista do trabalho. Tempo Social, São Paulo, v. 1, n. 2, p. 73103, 1989.

VILLAVICENCIO, D. Por una definición de la calificación de los trabajadores. Trabalho apresentado no 4. Congreso Español de Sociologia, Madrid, 1992. 